\title{
A review of the first 12 months of a hand clinic
}

\author{
P. A CUTTING \& N. R. McLEAN \\ Department of Plastic, Reconstructive and Burns Surgery, Queen Mary's University \\ Hospital, Roehampton, London, England
}

\section{SUMMARY}

The potential problems faced on setting up a hand clinic and how they may be overcome are discussed. In its first 12 months there were 199 new referrals over $50 \%$ of which were either lacerations, fingertip injuries or fractures. The management of these cases is discussed.

\section{INTRODUCTION}

Injury to the hand is a frequent occurrence accounting for between 13 and $21 \%$ of attendances at casualty departments (Clark et al., 1985; Wilson, 1986) and 32\% of the emergency referrals to a regional plastic surgery unit (McLean \& Cutting, 1986).

As the initial examination and management of the injured hand greatly influences the final result (Smith \& Jones, 1985), casualty officers must have specialized advice freely available 'on the spot' from a surgeon knowledgeable in the treatment of such cases.

Many hospitals already have an established hand clinic staffed by either the orthopaedic or plastic surgery department, but until recently there was no such clinic at our hospital. The authors wish to report on the potential problems faced in setting up a hand clinic, to discuss how they may be overcome and to review the first 12 months referral to such a venture.

\section{SETTING UP THE CLINIC}

In May 1984, the opportunity arose to set up a hand clinic. A list of the potential problems that might be encountered was drawn up (Table 1), the most important being

Correspondence: Mr Neil R McLean, Senior Registrar, Department of Plastic, Reconstructive and Burns Surgery, Queen Mary's University Hospital, Roehampton, London SW15 5PN, England 
Table 1 Potential problems to be faced when setting up a hand clinic

(1) Support of accident and emergency consultant

(2) Support of one's own consultant

(3) Availability of clinic space

(4) Availability of medical staff and nursing staff

(5) Easy access to physiotherapist, occupational therapist and plaster technician

(6) Suitable time for starting clinic

(7) Cover of colleagues during absence from sickness or annual leave

gaining the full support of the Consultant in Charge of the Accident and Emergency (A
\& E) Department.

An area of the Casualty department was partitioned off into three separate cubicles. (Fig. 1) and, in conjunction with senior nurses, it was arranged to hold the clinic weeklit at a convenient time when the department was relatively quiet. This was over and above the normal 24-h emergency service provided by the 'on-call' plastic surgery team. Two nurses were allocated to cover and the senior physiotherapist made arrangements to give 'on the spot' advice. Although, due to staff shortages, the occupational therapist waso unable to attend on a regular basis, open access was available to their department foe occupational therapy and the manufacture of splints.

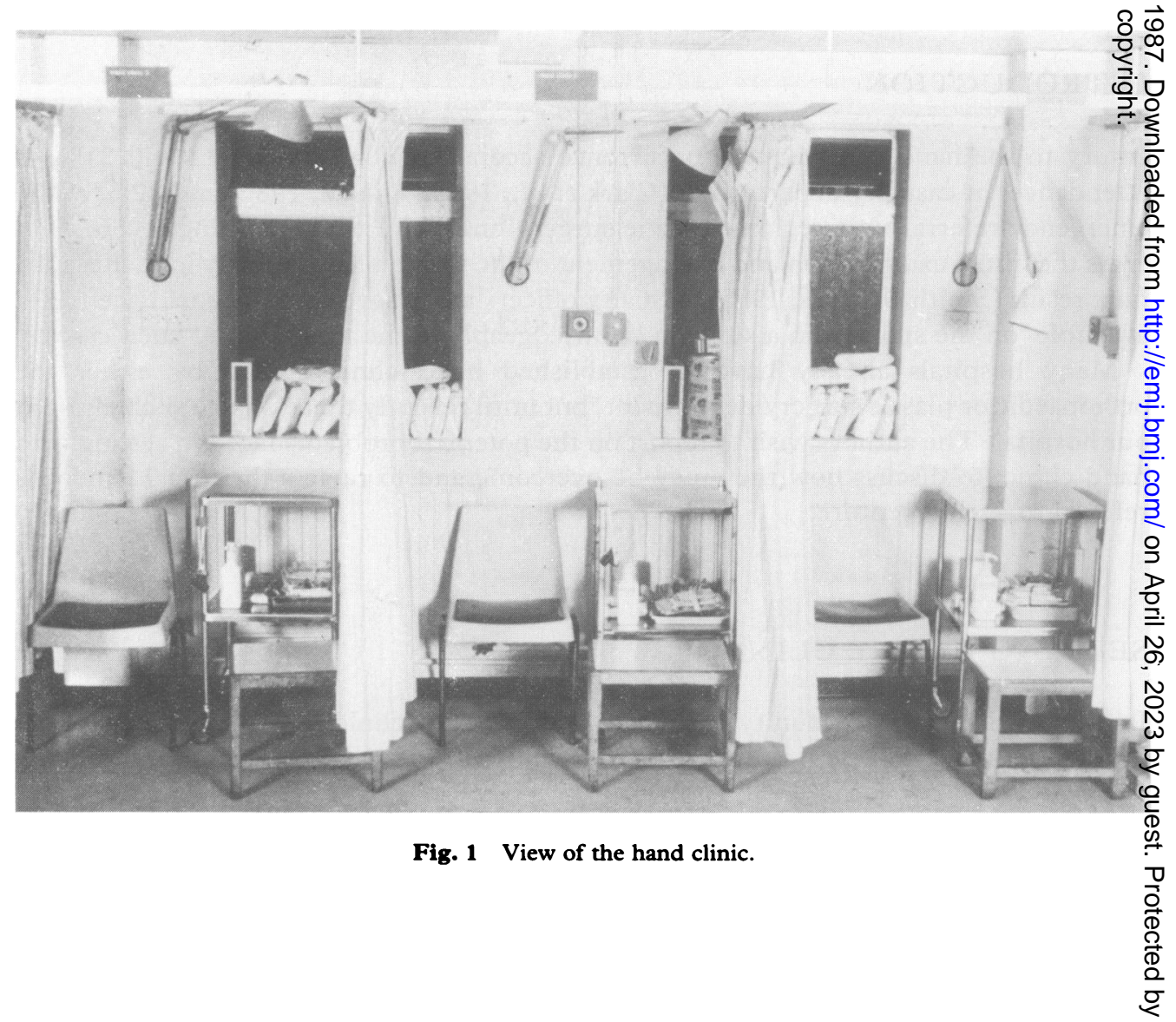


No restriction was placed on either the numbers or the types of cases referred. The majority of the patients had been treated in the A \& E department for a variable period of time prior to referral to the hand clinic.

\section{RESULTS}

In the first 12 months of the clinic, from 1 May 1984 to 30 April 1985, there were 366 attendances (Fig. 2) of which 199 were new referrals. Eighty-four per cent were referred from our own casualty officers (Table 2), $78 \%$ of the cases were male and the mean age was 35 years. Each patient attended 1.8 times on average and 65 patients refused to return for further treatment after the initial attendance. The type of injuries seen and their aetiology is shown in Tables 3 and 4 . The most common presentation (27\%) was a sutured skin laceration with no underlying tendon or neurovascular damage which was referred for a second opinion if there was a suspicion on clinical examination of a potential injury to the deeper structures (Fig. 3).

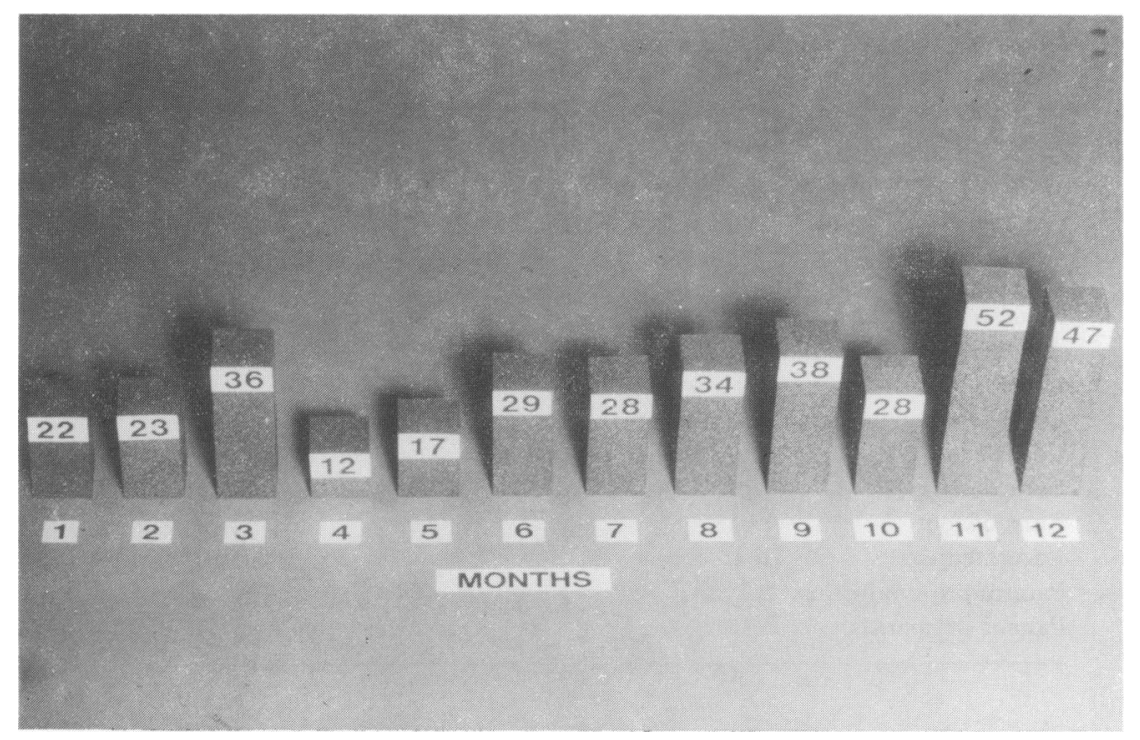

Fig. 2 Analysis of the monthly variation in total attendances.

Table 2 Sources of referral

\begin{tabular}{lr}
\hline Casualty Department & 167 \\
Other hospitals & 16 \\
Plastic surgery wards & 10 \\
Other wards in hospital & 3 \\
General practitioners & 1 \\
Others & 2 \\
\hline
\end{tabular}


Table 3 Cases referred to the hand clinic

No. of patients

Skin lacerations

Fingertip injuries

Fractures (total)

Phalanx

Metacarpal

MCP dislocation 2

Skin loss

Burns

Infection

Extensor tendon injury

Digital nerve injury

Foreign body

Dog bites

Unhealed wounds

Mallet finger

Flexor tendon injury

Pyogenic granuloma

Painful finger

Flexor tendon and digital nerve injury

Tender scar

Bruised finger

Palmar haematoma

Synovitis of wrist

Arm laceration

Other referrals

Nasal fracture

Anterior tibial lacerations

Laceration of heel

Divided musculo-cutaneous nerve

Leg ulcer

Camptodactyly

Burn of foot

Lacerated ear

Painful arc syndrome

Palmar dermatitis

2

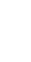

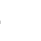




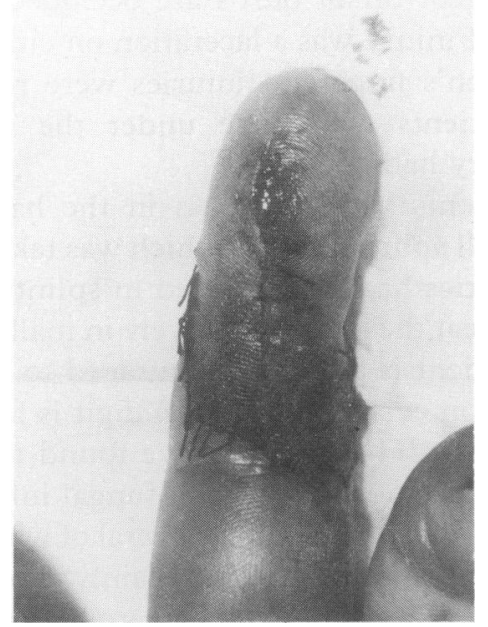

Fig. 3 Tightly sutured laceration of the index finger with impending necrosis of the skin flaps.

The next was a fingertip injury that was slow to heal. The majority of these were crushing injuries which had been treated prior to referral with a wide variety of different dressings, in some cases for up to 6-8 weeks. These injuries were treated with zinc oxide tape (Fig. 4a \& b). This was changed by the patient on a daily basis or earlier if soiling occurred. The fingertip wound initially becomes moist but quickly epithelializes under the occlusive dressing. This simple method has been used in the authors' unit for many years in the management of small burns and it is thought that the topical application of zinc in the tape accelerates wound healing.

The number of hand infections is, perhaps, a little low for a busy A \& E department but, during this period, a further 20 severe hand infections were admitted directly for parenteral antibiotics. As our casualty officers are well able to deal with the more minor hand infections, only the recalcitrant cases are referred to the clinic. All burned hands

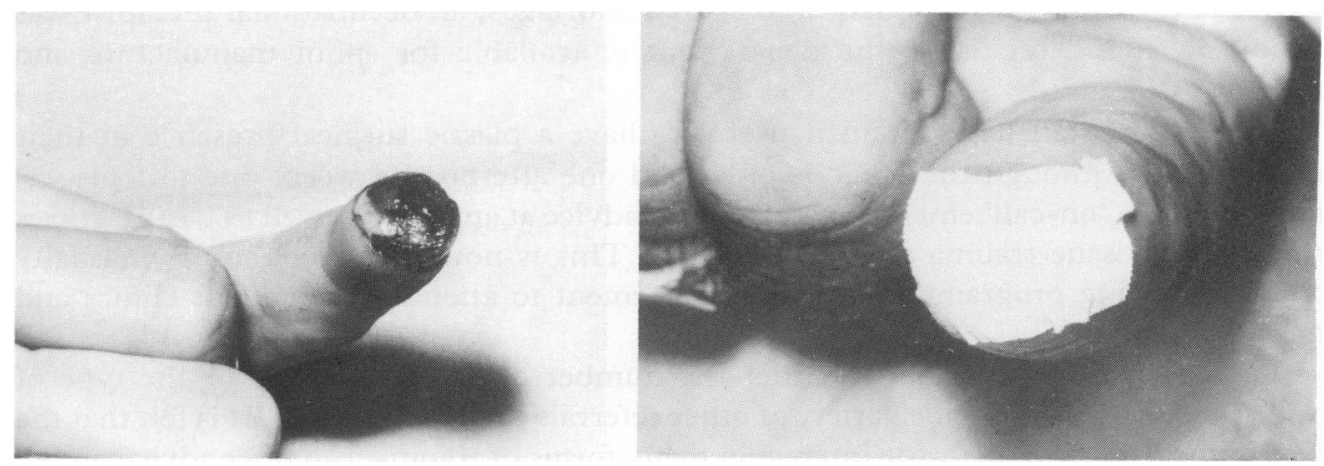

Fig. 4 (a) Unhealed wound of fingertip 2 months after injury. (b) Zinc oxide tape applied: this wound healed within 10 days. 
are treated in plastic bags filled with Flamazine as outpatients. These are changed daily and physiotherapy encouraged. Small burns are occluded with zinc oxide tape. Thez most common mechanism of injury was a laceration on either glass or metal (Table 4) $\stackrel{\mathbb{Q}}{\stackrel{1}{0}}$ The majority of the children's finger tip injuries were related to being caught in closing door. Thirteen patients who were under the influence of drink had no? recollection of how the injury had occurred.

The majority of the patients with skin loss in the hand healed without surgery产 although two required a small split skin graft which was taken under a local anaesthetic $\underset{\Omega}{\mathbb{D}}$ All of the mallet finger injuries had been treated in splints for up to 6 weeks prior tô referral. It is our policy to treat these conservatively in mallet finger splints for between $b$ 8 and 12 weeks, and the patient is actively encouraged to remove the splint daily and wash both it and the finger on condition that the digit is held extended on a table top during the washing procedure. The authors have found that this greatly reduces the problems with skin maceration and super added fungal infection. Similar treatment is also used in untreated Boutonniere deformity. Several of which have been seen recently

The majority of the injuries have been treated mainly in our own casualty department prior to referral and it is interesting to note there were 13 other patients with a variety of injuries varying from nasal fractures to anterior tibial lacerations. It is felt that this service is important as the plastic surgeon is 'on the spot' in the A \& E department to offer advice, not only on the hand injuries, but also on all kinds of soft tissue trauma.ळ

\section{DISCUSSION}

Although many hospitals have an established hand clinic, little has been written on either the problems associated with setting it up or the types of cases referred. In facto there are no publications listed under 'clinics' in the 15-year index of the British fourna of Hand Surgery. In setting up the clinic, the authors were fortunate in having the complete backing of the consultants and senior nurses involved, and they are extremely grateful to them for their help and advice.

One of the most important aspects of managing the acutely injured hand is the place of physiotherapy and it is essential to have a keen physiotherapist to give immediate advice and treatment. Although, due to staff shortages, an occupational therapist wasis unable to attend regularly, the department is available for splint manufacture and therapy as required.

The A \& E staff have found it useful to have a plastic surgical presence in their department. Although the clinic is only held one afternoon a week, due to logistics? there is a 24- $h$ 'on-call' emergency service for advice at any time as well as basic lectures run on soft tissue trauma and management. This is now a part of the new casualty officers teaching programme, as is encouragement to attend at outpatient clinics and theatre sessions.

As there is no restriction on either the number of cases attending or the type of injuries seen, there is a wide variety of other referrals treated (Table 2). It is felt that the plastic surgeon, with his wide interest in many forms of trauma, can offer advice on the management of many of the soft tissue injuries seen in the A \& E department. If the 
minor, but by no means trivial, injuries are properly dealt with then the major ones will receive the correct treatment. It is hoped that, if well taught, the casualty senior house officers should do better with the more serious forms of trauma.

During the first year of the clinic there were 199 new referrals attending on a total of 366 occasions. In the second year, this figure has increased to over 500 new referrals confirming the success of the venture.

Any case requiring in-patient treatment was admitted under a consultant hand surgeon.

Although many of the injuries referred were of a minor nature, if they receive the wrong or inappropriate treatment, then the rehabilitation of the patient, particularly the manual worker, is greatly prolonged leading to financial difficulties due to loss of earnings.

In conclusion, the authors present a review of the first 12 months of a hand clinic and discuss the potential obstacles to be overcome on setting it up. Looking towards the future, one would hope that a hand clinic could become a forum for a multi-disciplinary approach to the injured hand, allowing discussion between all the specialities interested in the management of these most interesting, but difficult, clinical cases.

\section{ACKNOWLEDGEMENTS}

We wish to thank Dr J. Thurston and Mr J. V. Jeffs for their enthusiastic support, the Department of Medical Illustration and Photography, and Mrs K. Savage for typing the manuscript.

\section{REFERENCES}

Clark D. P., Scott R. N. \& Anderson I. W. R. (1985) Hand problems in an accident and emergency department. Fournal of Hand Surgery 10B, 297-9.

McLean N. R. \& Cutting P. A. (1986) A 12-month review of the emergency referrals to a regional plastic surgery unit. British fournal of Accident and Emergency Medicine 1, 5-8.

Smith P. J. \& Jones B. M. (1985) Care of the acutely injured hand. British Medical fournal 290, 178-9.

Wilson P. (1986) A spectrum of hand injuries. British fournal of Accident and Emergency Medicine 1, 25-7. 